\title{
Fracture Surface of Polyester/Areca Nut Fiber Composite Under Impact and Tensile Loading
}

\author{
Sulaiman Thalib *, Nurdin Ali, Husni, Frendy Imanuddin \\ Department of Mechanical and Industrial Engineering, Faculty of Engineering, Universitas Syiah Kuala, Jl. \\ Syekh Abdurrauf No. 7, Banda Aceh 23111, Indonesia \\ * Corresponding author: sulaimanthalib@unsyiah.ac.id
}

\begin{abstract}
Studies in this paper relate to the development of composite materials. Special attention is given to the development of polymer composite materials which are reinforced with natural fibers. At present a very intense investigation using local materials sources. This paper presents an analysis of surface fractures caused by Charpy impact and tensile loading. Specimens prepared in this study used polyester resin $85 \%$ by weight, and areca nut fiber which has been boiling with $100 \mathrm{oC}$ of boiling water for 6 hours of $15 \%$ by weight. The making of polyester matrix composite material with areca nut fiber reinforcement material that has undergone physical treatment is done by mixing. This mixture was entered into the mold that has been prepared for the tensile test specimen and impact test specimen. The mold that has been filled with the composite material is pressed with a high-pressure press to get a solid composite material and reduce cavities. Fracture surface of specimens due to impact tests and tensile tests are examined using a scanning electron microscope. The results of the analysis of the fracture surface in tensile loading showed that the fiber was broken evenly with the matrix breaking. While the fracture surface that occurs in the tensile loading shows a very fibrous fracture surface where the broken fiber is not on the broken surface but as if it was pulled from the matrix. On the fracture surface the tensile test and impact test specimens reveal very little cavities and the visible gaps between the fiber and the matrix are very small. This shows the bond between the fiber matrix is good.
\end{abstract}

Key words : Surface fracture, areca nut fiber, Polyester matrix composite, mechanical properties.

\section{INTRODUCTION}

The use of polymer matrix composite materials reinforced with glass fiber and carbon fiber materials has been able to replace some metal and wood materials since the development of composite materials began in the middle of the last century, [1, 2]. However, the use of polymer composite materials reinforced with artificial fibers is considered environmentally unfriendly $[3,4]$ because the material is not able to decompose naturally or non-biodegradable [5].

Based on the consideration of these environmental problems, a substitute for artificial fiber is needed and based on previous research, the most suitable material for its replacement is natural fiber [6-8]. Natural fiber has several advantages, namely strength and stiffness, which almost resemble artificial fibers [9] cheap, easily obtained, renewable [10,11], non-toxic [12]. The combination of natural fibers with polymers raises another problem, namely natural fibers are hydrophilic while polymeric materials are hydrophobic, this creates a mismatch between the polymer material and natural fiber material as reinforcement $[4,12,13]$. In order to increase suitability it is necessary to modify the surface of natural fibers [15] namely physically [16-18], and chemically $[18,19]$. The process of physical modification can also be done by boiling [20, 21].

The main performance of polymer composite materials which are reinforced with natural fibers, must have a strong enough bonding interface, so the matrix are able to move the load to the reinforcing fibers. The composition of the fiber contained in the composite is an important parameter that plays a role in determining the properties of the composite [22, 23]. Composite material performance testing can be done in various ways including by conducting impact testing, tensile testing and analyzing the morphology of materials and can also be done by analyzing the fracture surface of materials due to damage [24]. As it is known that in impact testing is giving a load at high speed to the material being tested, whereas tensile testing is giving a slower load here will result in a fracture pattern that is different from the two types of loading.

In another study, conducted by Mahoto [25]. on epoxy matrix composite materials reinforced with glass fibers, by giving different loading rates performed by tensile testing, showed the strength of the composite material was different but the modulus of elasticity did not change, and showed also the strain until it fails also increases with increasing loading rate. 
The surface morphology of the fracture is studied to identify the location of the origin of the crack and to determine the mechanism of crack propagation. The fracture surface evaluation and morphology due to loading can be done by impact testing and tensile testing [26]. In this investigation, the study was focused on analyzing the surface fracture of composite materials reinforced with areca nut fiber. The objective of this study is to analyze the morphology of the fracture surface resulted tensile and impact test with several fiber compositions and different loading, So that it can be seen the fracture behavior and the quality of bonding between areca nut fiber and polyester matrix.

Further studies can consider some research in related works [27-29]

\section{EXPERIMENTAL PROCEDURE}

\subsection{Materials: Areca Nut Fiber}

Areca nut fiber is the result of plantation waste that is peeled from the seeds obtained from the South Aceh Region. Before being used as a reinforcing fiber for composite materials, areca nut fiber is first dried to remove the water content of the fruit that is still in the skin. Furthermore, physical treatment is carried out to modify the surface of the fiber so that it can improve the bonding ability with the matrix. This physical treatment process is carried out by boiling fiber in water at a temperature of $100{ }^{\circ} \mathrm{C}$ for 6 hours, and then dried with sunlight. To reduce the moisture content that is still present in the fiber, before drying, it is carried out at $100{ }^{\circ} \mathrm{C}$ for 1 hour.

\subsection{Resin and Hardener}

The matrix material used for the manufacture of composite materials is clear polyester resin number 102 . To accelerate the hardening of the matrix material, polyester is mixed with the hardener, the hardener composition in the resin is $1 \%$ so that it has enough time to process the composite material used for the specimen before the resin hardens.

\subsection{Composite Manufacturing Process}

The process used in making composites is the mixing of fibers with a matrix, this is because the length of areca nut fiber is difficult to do with the hand lay up method. The mixture of resin and hardener is then mixed with areca nut fiber according to a predetermined composition. Mixing is done in a container.

The mixture of fiber and resin is then put into a mold and then pressed with a high pressure press machine of around 60 tons, so this load is expected to release the trapped air in the composite material mixture. These high pressures can also form denser composites with fewer pores, The mold is removed after finishing the curing process for around 12 hours. Two composite plates were molded for impact test specimens with a thickness of $10 \mathrm{~mm}$ and for tensile test specimens with a thickness of $3 \mathrm{~mm}$. The process of making specimens for impact testing refers to ASTM E23-07, while the tensile testing specimens in this study refer to ASTM D-638.

\subsection{Tensile Testing}

Composite plates that have been made in the same composition as impact test specimens with a thickness of 3 $\mathrm{mm}$. The composite plates are then cut to make tensile test specimens according to E658 standard. The making tensile test specimens using a milling machine. The tensile test specimen that has been prepared is carefully installed into the testing machine, then the load given is controlled and the length of the specimen is measured. Tensile testing of specimens is carried out using a universal testing machine at a tensile speed of $2 \mathrm{~mm}$.

\section{RESULT AND DISCUSSION}

The tensile properties is part of the mechanical properties of the materials, this property shows how the force acting in the direction of pull can be responded to by the material, tensile property can be determined by performing tensile testing. Tensile testing is a very basic mechanical test, where the specimen is prepared according to the test standard. The tensile testing is carried out to determine elastic limits, proportional limits, elongations, reduction in area, modulus of elasticity, tensile strength, yield strength, yield points, Poisson ratio, and other tensile properties such as fracture surface behavior.

Impact properties are material properties that show toughness, impact properties can be determined by giving impact loads to the material. The energy absorbed by the material during impact testing is the level of toughness of the material. The more energy absorbed indicating that the material is more ductile. This can be confirmed with the fracture surface of material that occurred at the time of impact test. The features of the fracture surface of the material can determine the brittle or ductile of the material. Furthermore, it only discusses fracture surface features to get an idea of the damage to the composite material that might occur.

The fracture surfaces are two surfaces that are formed due to a fracture material, while fracture is the separation of an object or material into two or more pieces due to the action of stress. A material fracture can occur due to the development of crack length or crack propagation into the material. The fracture surface of this material can be used to analyze material properties such as brittle properties and ductile and can also be used to study the failure of material. To study the fracture surface in macro can be done by observing the fracture surface using the naked eye, but if it can not be concluded the results of observation with the naked eye can be continued 
observation using an optical microscope, laser confocal microscope or by using a scanning electron microscope. Fracture surface characteristics are analyzed to infer the cause of the failure. The morphology of fracture surface also can be used to determine the quality of a material.

The fracture of the specimen after impact testing can be seen in Figure 1. while the fracture by tensile testing is shown in Figure 2. Both of these images show macroscopic fractures in various compositions, respectively for specimens with different composition of polyester and areca nut fiber that is $5 \%, 15 \%$ and $25 \%$ by the weight of fibers in the composite. Specimens that experience Charpy impact loads (Figure 1) show that with the increasing fiber content, the characteristics of the material are more resilient. Fractures of specimens subjected to tensile loading for all compositions did not show differences in surface characteristics of fractures, and all exhibited as brittle characteristics as shown in Figure 1.

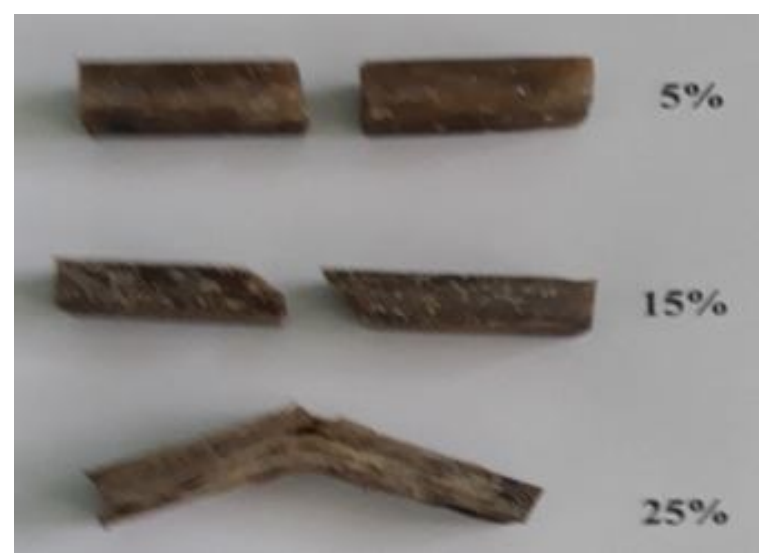

Figure 1: Specimen fracture due to charpy impact test

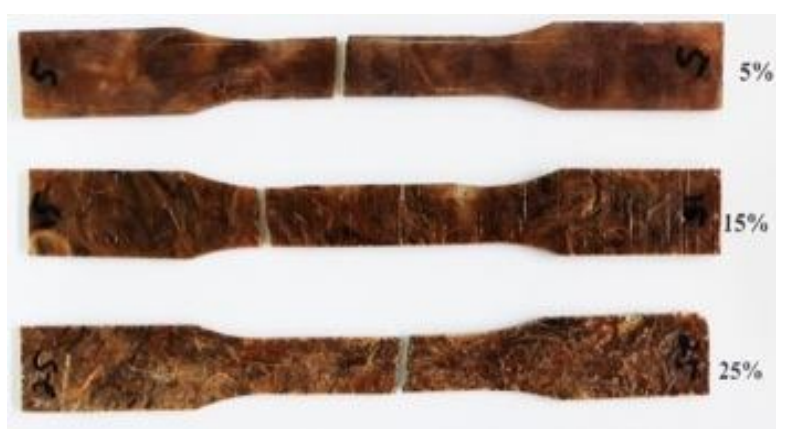

Figure 2: Specimen fracture by tensile test.

The Charpy impact test for specimens with 25\% fiber content shows the characteristics of composite material specimens appear to be very resilient compared to other lower compositions. In Figure 1 with a fiber content of $25 \%$ the specimen did not break completely or was not separated in two parts after impact. This happens because cracks cannot propagate into the matrix, caused by the more dominant fiber content in the matrix thereby blocking crack propagation. In this composition, if all the fibers are cut off, the specimens will separate into two parts, thus requiring greater absorption of energy for crack opening. Impact surfaces fracture for specimens with the fiber composition up to $15 \%$ by weight all show brittle fracture surfaces, the crack begins at the notch on the surface of the specimen and propagates transversely, and cuts the matrix to cause a perfect fracture. The result shows the similarity of the phenomenon as described by Pereira et. al. [2] who used impact specimens from epoxy composite materials reinforced with jute fibers.

In general, this composite material for various fibers compositions shows that the direction of the fiber arrangement is not aligned or shows the arrangement of fibers randomly. From the fracture surface there are also voids in the composite matrix. This void is partly a trace of fiber that is uprooted when crack opening occurs, while voids with larger sizes indicate the presence of air trapped during processing.

Figures $3 a$ to $3 c$ of micrograph photo results using SEM at 30x, 100x, and 250x magnification respectively, This image shows a broken surface on one side. Figures $3 \mathrm{~d}$ to $3 \mathrm{f}$ show broken surfaces on the other side. On Charpy impact loading with a composition of $15 \%$ by weight of fiber shows a more obvious surface fracture mechanism compared to other compositions. If observed with a greater magnification of 250X, the fracture surface shows unequal conditions for both sides, on one side it shows a smooth surface condition and also shows the void, surface conditions on the other side, show more rough conditions. Both sides of the fracture do not indicate a gap between the fiber and the matrix. Because it shows a good adhesion between the fiber and the matrix while the void is formed during processing due to trapped air.
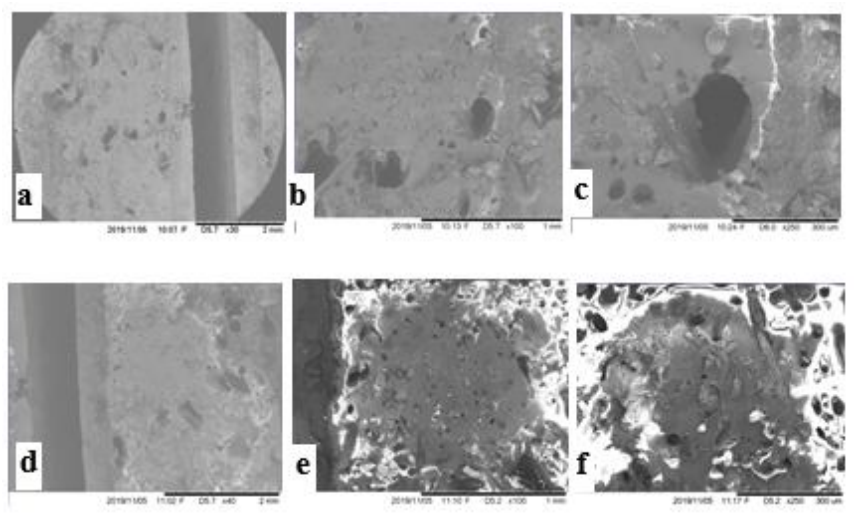

Figure 2 : Fracture surface under impact charpy loading, specimen $15 \%$ weight fiber, (a), 30x (b) $100 \mathrm{x}$ (c) $250 \mathrm{x}$, on the other side (d) $40 \mathrm{x}$, (e) $100 \mathrm{x}$ and (f) $250 \mathrm{x}$ 

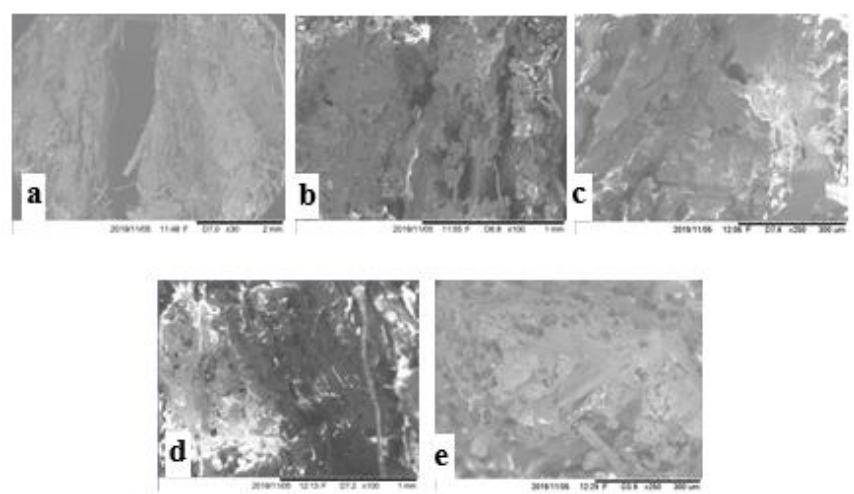

Figure 3: Fracture surface under impact charpy loading, specimen of $25 \%$ weight fiber, (a), 30x (b) 100x (c) 300x, on the other side (d) $100 \mathrm{x}$ and (3) 300x

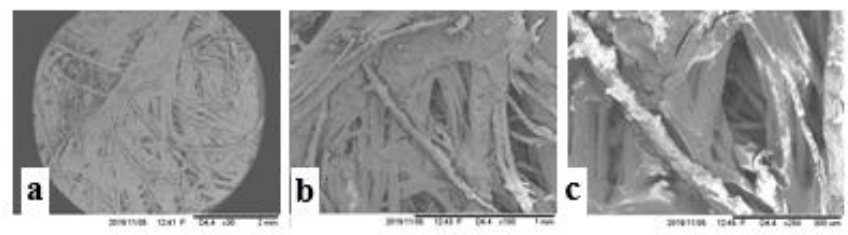

Figure 4: Fracture surface of the charpy impact loading, specimen with the composition of $25 \%$ by weight and longitudinal direction, (a) 30x, (b) 100x dan (c) 250x
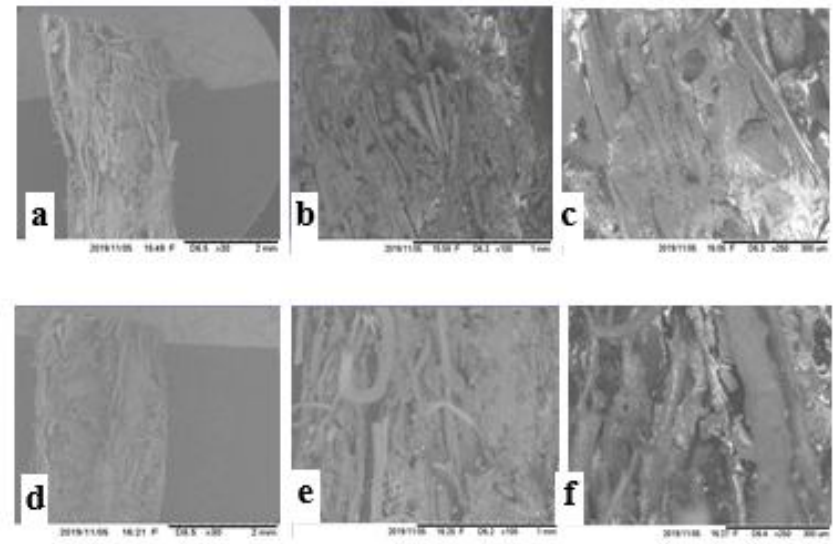

Figure 5: Fracture surface under tensile loading, specimen 25\% weight fiber, both of part (a) 30x, (b) 100x and (c) 300x, other side (d) $30 x$, (e) $100 x$, (f) $300 x$

To clearly see the fracture surface of a composite material with a 25\% fiber composition can be observed in Figures 4a to $4 \mathrm{e}$, from this figure, it can be seen the fracture condition where the fracture surface does not show any gaps between the fiber and polyester matrix, this shows that most of the fracture area appears a good adhesive between the two materials. When observed from the side of the fiber on the fracture surface in the image it can also be seen that the fiber can be cut off, partially pulled so as to see the condition of the form of the stringy surface. When compared with $15 \%$ fiber composition composites which show smoother fracture surfaces, then composites with greater fiber content become more ductile.
In the thick direction of the specimens with a composition of $25 \%$ by weight of the fiber it is found that there is separation or splitting as shown in Figure 1 while the fractography can be seen in Figures 5a through 5c. Separation occurs because of the energy absorbed when the crack opening is blocked by fiber, then some of the energy spreads towards the longitudinal specimen, resulting in delamination between fibers and polyester which form longitudinal fractures or show split cracks, this shows a decrease in interface strength between the fiber and the matrix. The same situation was also reported by other researchers as reported by Pereira et. al. [2].

The surface fracture characteristics on the tensile loading shows a difference with the impact surface fracture impact characteristics. On tensile loading the fracture surface shows more stringy because the tip of the fiber is pulled out of the matrix as shown in Figure 6. In the picture can also be seen fracture surface also shows the fibers in the transverse direction of the specimen, this shows that the arrangement of fibers in the composite is random. If viewed from the aspect of loading speed, tensile testing is carried out using a pull speed of $2 \mathrm{~mm} /$ minute, with this velocity the fracture opening also occurs slower than the fracture opening at the impact loading. As is known the speed of loading the impact test is much faster than the speed of loading the tensile test. Testing conditions with slow tensile speeds can cause fibers to be pulled out of the matrix, and some of the matrices on the fracture surface are destroyed. The fracture surfaces in the same specimen can be seen in the transverse direction as Figure 7a to 7c. Consequence of the fiber being torn out and the matrix destroyed, the fracture surface is very rough and many ends of the fibers protrude out into the form of fibers.
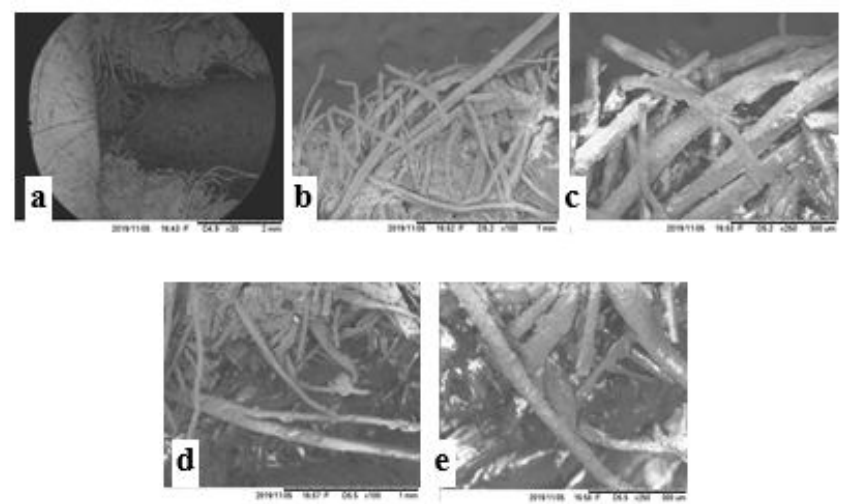

Figure 6: Facture surface under tensile loading. specimen $25 \%$ weight fiber, view on transversal direct, (a) both of part fracture 30x, (b) 100x, (c) 250x, other side (d) 100x, (e) 300x

\section{CONCLUSION}

In this investigation, analyzing the fracture surface behavior caused by loading the Charpy impact, and tensile loading of polyester matrix composite material with areca fiber reinforcement material that was physically treated. From the above discussion several conclusions can be drawn. 
Polyester matrix composite material reinforced with areca nut fibers shows increasingly ductile behavior with the increasing fiber content, this can be demonstrated by interpreting the composite fracture surfaces at different compositions by Charpy impact testing.

The fracture surface pattern that occurs due to impact loading and tensile loading shows different fracture patterns, on impact loading the fracture surface pattern shows a flatter and finer shape, while the fracture surface pattern on tensile loading shows a rough and stringy fracture surface. This is because of differences in speed and direction of loading.

Specimen $25 \%$ by weight fiber, found that there is a separation or splitting, Separation occurs because of the energy absorbed then some of the energy spreads towards the longitudinal specimen, resulting in delamination between fibers, and polyester which form longitudinal fractures or show split cracks, this shows a decrease in interface strength between the fiber and the matrix.

\section{ACKNOWLEDGEMENT}

The authors would like to express their gratitude to Universitas Syiah Kuala for their financial support for this research through the grant No. 218/UN11.2 / PP/ PNBP/ SP3/2019. The authors would also like to thank the Department of Mechanical and Industrial Engineering, Universitas Syiah Kuala, Banda Aceh, for providing facilities.

\section{REFERENCES}

1. K.K. Chawla. Composite materials science and engineering, 3rd ed. New York: Springer : 2012.

2. A.C. Pereira, S.N. Monteiro, F. Salgado de Assis, F.M. Margem, F. Santos da Luza, F. O. Braga. Charpy impact tenacity of epoxy matrix composites reinforced with a ligned jute fibers, Journal of Materials Research and Technology 6(4), 312-316, 2017.

https://doi.org/10.1016/j.jmrt.2017.08.004

3. S.N. Monteiro, F.P.D. Lopes, A.S. Ferreira, D.C.O. Nascimento. Natural fiberpolymer matrix composites: cheaper, tougher and environmentally friendly, JOM: the journal of the Minerals, Metals \& Materials Society 61(1):17-22, 2009. doi: 10.1007/s11837-009-0004-z

4. P. Wambua, I. Ivens, I. Verpoest. Natural fibers: can theyreplace glass in fibre reinforced plastics? Composites Science and Technology, 63(9), 1259-1264, 2003. https://doi.org/10.1016/S0266-3538(03)00096-4

5. D. Fouad, D, and M. Farag. Design for Sustainability with Biodegradable Composites, Design Engineering and Manufacturing, 2019. doi: 10.5772/intechopen.88425

6. K.L. Pickering, M.A. Efendy, T.M. Le. A review of recent developments in natural fibre composites and their mechanical performance, Composites Part A: Applied Science and Manufacturing, 83, 98-112, 2016. https://doi.org/10.1016/j.compositesa.2015.08.038

7. J. Summerscales, N. Dissanayake, A.S. Virk, W. Hall. A. review ofbast fibres and their composites, Composites Part A:Applied Science and Manufacturing, 41(10). 1329-1335, 2010.

DOI: 10.1016/j.compositesa.2010.06.001

8. S. Thalib, S. Huzni, S. Fonna, C.H. Azhari, S. Zakaria. The effect ofparticle compositions on the activation energy of the pa6/bagassecomposite, IOP Conf. Series: Materials Science and Engineering, 602(01) 012086, 2019. doi:10.1088/1757-899X/602/1/012086

9. J. Sliseris, L. Yan, B. Kasal. Numerical modelling of flax short fibre reinforced and flax fibre fabric reinforced polymer composites. Compos. Part B Engineering, 89, 143-154, 2016.

10. V.G. Gethamma, K.T. Mathew, R. Laksminarayanan, R, and S. Thomas. Composite of Short Coir Fibres and Natural Rubber:Effect on Chemical Modification, Loading and Orientation of Fibre, Journal Polymer. 39(6-7): 1483-1491, 1998. https://doi.org/10.1016/S0032-3861(97)00422-9

11. P.H. Joseph, M.S. Robello, L.H.C. Mattoso, K. Joseph, and S. Thomas. Enviroment Effect on The Degredation Behaviour of Sisal Fibre Reinforced Polypropylene Composites, Journal Composite Science and Technology 62(10-11) : 1357-1372, 2002. https://doi.org/10.1016/S0266-3538(02)00080-5

12. A. Ayensu. Interfacial Debonding of Natural Fiber Reinforced Composite, Quart Sci Vision, 6, 25-34, 2000.

13. S. Rizal, D.A. Gopakumar, S. Thalib, S. Huzni, and H.P.S.Abdul Khalil. Interfacial Compatibility Evaluation on the Fiber Treatment in the Typha Fiber Reinforced Epoxy Composites and Their Effect on the Chemical and Mechanical Properties, Polymers (Basel). 10(12): 1316, 2018.

doi: 10.3390/polym 10121316

14. O. Faruk, A.K. Bledzki, H.P. Fink, M. Sain. Biocomposites reinforced with natural fibers: 2000-2010, Proggress in Polymer Science, 37(11), 1552-1596, 2012. https://doi.org/10.1016/j.progpolymsci.2012.04.003

15. X. Li, L.G. Tabil, S. Panigrahi, and W.J. Crerar. The influence of fiber content on properties of injection molded flax fiber-HDPE biocomposites, In 2006 ASAE annual meeting (p. 1). American Society of Agricultural and Biological Engineers, 2006.

DOI: $10.13031 / 2013.22101$

16. M.Z. Rhong, M.Q. Zhang, Y. Liu, G.C. Yang, and H.M. Zengl. The effect of FiberTreatment on The MechanicalPrperties of Undirectional Sisal 
Reinforced Epoxy Composites, Journal Composite Science and Technology, 61(10): 1437-1447, 2001. https://doi.org/10.1016/S0266-3538(01)00046-X

17. N.E. Zafeiropoulos, D.R. Wiiliams, C.A. Baillie, and F.L. Matthews. Engineering and characterisation of the interface flax fibre/polypropylene composite materials. Part I. Development and investigation of surface treatments, Composites Part A:Applied Science and Manufacturing, 33(8) : 1083-1093, 2002.

https://doi.org/10.1016/S1359-835X(02)00082-9

18. M.N. Zakaria. Effect of hot water fibre treatment on the properties of kenaf/polyester composites, Doctoral dissertation, University of New South Wales, 2014. http://unsworks.unsw.edu.au/fapi/datastream/unsworks: 11911/SOURCE02?view=true

19. S. Rizal, D.A. Gopakumar, S.Huzni, S.Thalib, M.I. Syakir, F.T. Owolabi, N.A. Sri Apprilia, M.T. Paridah, and H.P.S. Abdul Khalil. Tailoring the effective properties of typha fiber reinforced polymer composite via alkali treatment, Bioresources, 14(3), 5630-5645, 2019.

20. S.T. Georgopoulos, P.A. Tarantili, E. Avgerinos, A.G. Andreopoulos, and E.G. Koukios. Thermoplastic polymers reinforced with fibrous agricultural residues, Polymer Degradation and Stability, 90(2) : 303-312, 2005.

https://doi.org/10.1016/j.polymdegradstab.2005.02.020

21. D. Cho, J.M. Seo, H.S. Lee, C.W. Cho, S.O. Han, and W.H. Park. Property improvement of natural fiber-reinforced green composites by water treatment, Advanced Composite Materials, 16(4), 299-314, 2007.

22. S. Rizal, Y. Nakai, D. Shiozawa, H.P.S. Abdul Khalil, S. Huzni, and S. Thalib. Evaluation of Interfacial Fracture Toughness and Interfacial Shear Strength of Typha Spp. Fiber/Polymer Composite by Double Shear Test Method, Materials, 12, 2225, 2019. doi:10.3390/ma12142225
23. K.E. Perepelkin. Chemistry and Technology of Chemical Fibres: Principle and Methods of Modification of Fibres and Fibre Materials, A Review. Fibre Chemistry 37(2): 123-140, 2005. https://doi.org/10.1007/s10692-005-0069-6

24. S. Rizal, S. Thalib, and S. Huzni. Hemicellulose and lignin removal on typha fiber by alkali treatment. IOP Conf, Series: Materials Science and Engineering, 352(1), 012019, May, 2018. doi:10.1088/1757-899X/352/1/012019

25. K.K. Mahato, M. Biswal, D.K. Rathore, R.K. Prusty, K. Dutta, and B.C. Ray. Effect of loading rate on tensile properties and failure behavior of glass fibre/epoxy composite. IOP Conf, Series: Materials Science and Engineering, 115(1), 012017, Feb. 2016. doi:10.1088/1757-899X/115/1/012017

26. S.Koppula, A. kumar Kaviti, K. kumar Namala. Experimental Investigation of Fibre Reinforced Composite Materials Under Impact Load, IOP Conf. Series: Materials Science and Engineering, 330(1), 012047, 2018.

DOI: https://doi.org/10.1088/1757-899X/330/1/012047

27. M.Bhandari, Mechanical Computations of Functionally Graded Material Plate Subjected to Transverse Load, International Journal of Emerging Trends in Engineering Research, 8(4), 1034 - 1039. https://doi.org/10.30534/ijeter/2020/13842020

28. A. Yulianto, R. Soenoko, W. Suprapto, A. Sonief and A. S. Darmawan, Hardness and wear resistance improvement of Ferro Casting Ductile for permanent mold, International Journal of Emerging Trends in Engineering Research, 8(3), 617 - 622. https://doi.org/10.30534/ijeter/2020/02832020

29. A.E. Ismail and A.F. Mat Beyi, A Brief of Sources of injury and failure during stent implantation, International Journal of Emerging Trends in Engineering Research, 8(3), $667-673$. https://doi.org/10.30534/ijeter/2020/10832020 